\title{
UBERIZAÇÃO DO TRABALHO, SUBORDINAÇÃO JURÍDICA E DEPENDÊNCIA ECONÔMICA
}

\author{
UBERIZATION OF WORK, LEGAL SUBORDINATION AND ECONOMIC \\ DEPENDENCE
}

\author{
Murilo Carvalho Sampaio Oliveira ${ }^{1}$
}

\section{RESUMO}

$\mathrm{O}$ artigo discute as ideias de subordinação jurídica e dependência econômica no contexto daqueles que laboram em plataformas digitais, especificamente no modelo Uber. Inicia pela demonstração dos problemas provocados pela dimensão clássica (fordista) da noção de subordinação jurídica diante da uberização e em antigas relações flexíveis. Para compreender adequadamente quem deve ser o sujeito protegido pelo Direito do Trabalho, recorre-se à economia política clássica para delinear os traços do trabalho assalariado no capitalismo. A par da contribuição interdisciplinar, apresenta-se uma dependência econômica ressignificada, refutando as conhecidas críticas à ideia, de modo a considerar que a antiga noção de dependência econômica era superficial. No caso do modelo da Uber, indica como os métodos de controle, em especial o dirigismo econômico, caracterizam a noção de dependência econômica. Com o método dialético, foram empregadas técnicas de pesquisa de análise bibliográfica e documental.

Palavras-chaves: Uberização. Assalariamento. Relação de emprego. Subordinação jurídica. Dependência econômica.

\section{ABSTRACT}

The article discusses the ideas of legal subordination and economic dependence in the context of those who work on digital platforms, specifically the Uber model. It begins by demonstrating the problems caused by the classical (Fordist) dimension of the notion of legal subordination to uberization and in old flexible relationships. In order to adequately understand who should be the subject protected by labor law, classical political economic sisused to out line the traits of wage labor in capitalism. Along with the interdisciplinary contribution, there is a resigned economic dependence, refuting the well-known criticisms of the idea in order to consider that the old notion of economic dependence was superficial. In the case of the Uber model, it indicates how control methods, especially economic dirigisme, characterize the notion of economic dependence. With the dialectic method, bibliographic and documentary analysis research techniques were employed.

Keywords:Uberization. Employment. Employmentcontract. Legal subordination. Economicdependence

\footnotetext{
${ }^{1}$ Juiz do Trabalho na Bahia e Professor Associado da UFBA, Especialista e Mestre em Direito pela UFBA, Doutor em Direito pela UFPR e Pós-Doutorando pela UFRJ.
} 


\section{INTRODUÇÃO}

Na economia digital contemporânea, o novo modelo de negócios -plataformasdigitais vem englobando setores da economia de transportes, serviços, profissionais liberais, entre outros. Essas plataformas criam um mercado de pessoas conectado com os consumidores que necessitam de serviços específicos oferecidos por outras pessoas. A virtualidade da interconexão promove o encontro do trabalhador prestador com o consumidor, sujeitos que dificilmente se encontrariam por meios físicos ou presenciais.

No entanto, nessas plataformas vários riscos do negócio são repassados ao trabalhador, a exemplo do cancelamento das chamadas do tempo de espera não remunerado e o risco social de doença ou acidente, além das despesas com equipamentos ou veículos. Isto porque os trabalhadores destas plataformas são postos, no prisma formal-contratual, na posição jurídica de parceiros autônomos. São tidos como livres para se ativar ou desativar no horário de sua escolha, contudo por ganharem tão pouco são impelidos sempre a trabalhar o máximo da jornada fisicamente possível. Curioso que na condição de autônomos, não tem autonomia para fixar o preço de seu trabalho, recusar clientes ou mesmo avaliar seu parceiro, a plataforma eletrônica.

Em suma, esta contemporaneidade do trabalho em plataformas digitais renova a avaliação da eficácia e dimensão do critério de subordinação jurídica como nota distintiva do Direito do Trabalho. Fora da noção clássica de "subordinação jurídica", estes trabalhadores dependentes são excluídos da tutela legal da relação de emprego, inclusive padecendo de extensas jornadas e baixas remunerações nos trabalhos "uberizados". Entretanto, a realidade destes dependentes desprotegidos repete o problema da excessiva exploração do trabalhador que culminou no surgimento do Direito do Trabalho, embora o faça através de formas distintas da relação de trabalho subordinado clássica. Não obstante, tem-se indubitavelmente repetida a condição originária trabalhista: uma parte hipossuficiente que carece de proteção legal ante ao poder econômico do seu tomador de serviços. A desigualdade das partes nestas novas relações de trabalho persiste, ensejando a necessidade de um tratamento diferenciado e protetivo.

No âmbito normativo brasileiro, a Constituição Federal de 1988, que irradia seus princípios e valores no sistema normativo, elenca como seu fundamento a dignidade da pessoa humana (art. $1^{\circ}$, III). Para além da constitucionalização da tutela do trabalhador $\left(\right.$ art. $7^{\circ}$ ), o ordenamento jurídico brasileiro estabelece a proteção ao trabalho como um dos seus valores fundamentais e objetivos do Estado Brasileiro. Neste contexto valorativo constitucional, o sistema normativo trabalhista tem objetivo proteger os trabalhadores (expressão literal do art. $7^{\circ}$ ), cabendo a reinterpretação da CLT a fim de cumprir o programa constitucional, na direção da 


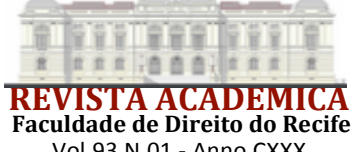

Vol.93 $\mathrm{N}$

noção ampla de empregado, notadamente pelo viés da acepção de trabalho dependente.

Nesta contextualidade, a dependência econômica apresenta-se como um critério distintivo da relação de emprego capaz de comportar as diversas manifestações atuais de trabalho assalariado, inclusive hábil a desvendar criticamente a atipicidade de certas formas de trabalhar e elucidar algumas ocultações do assalariamento disfarçado. Em outras palavras, a questão cingese a tentar rearticular a sinonímia entre empregado e assalariado, a qual, atualmente, não se realiza adequadamente pelo critério da subordinação jurídica. Defende-se que a tradução jurídica da noção de assalariado corresponde a ideia de dependência econômica.

Vale lembrar que a dependência econômica é uma ideia antiga, cuja aplicação foi recusada apenas por "razões doutrinárias", até porque o texto legal ("sob dependência") mais se aproxima semanticamente da dependência econômica do que da subordinação jurídica. No entanto, a noção antiga de dependência econômica, considerada aqui "epidérmica", não atende, da mesma forma, as expectativas contemporâneas. Valendo-se do método dialético, foram empregadas técnicas de pesquisa de análise bibliográfica e documental na elaboração deste texto.

\section{ROMPENDO COM A SUBORDINAÇÃO DISTINTIVA}

No bojo do pós-fordismo e da crise do Direito do Trabalho, novos e velhos problemas são colocados para a subordinação jurídica. Percebe-se que a marca da sujeição hierárquica do trabalhador foi atenuada ou diluída pelas dinâmicas de gestão do trabalho mais flexíveis, tornando mais difícil - pelo olhar tradicional - visualizar o mesmo assalariado, por força dos seus novos epítetos, como o (antigo) empregado. O novo do modismo contemporâneo disfarça, ilude e simula o velho padrão capitalista de trabalho assalariado, valendo-se de categorias e contratos de parceria, colaboração, autonomia, entre outros.

Os problemas do conceito de subordinação já iniciam pela sua própria definição. No debate histórico-doutrinário do juslaboralismo, a noção de subordinação jurídica pode ser dividida em dois sentidos bem demarcados. No sentido subjetivo, consiste em ordens e disciplina, fundada na ideia de poder, sendo esta a concepção hegemônica. No sentido objetivo, relaciona-se com inserção em produção alheia, por ausência de domínio dos fatores de produção, fundando-se na ideia de organização (ou propriedade), sendo esta posição minoritária.

Cotejando a concepção hegemônica, infere-se que a escolha pela subordinação hierárquica corresponde a uma grande mudança de foco, no sentido de, desprezando as características pessoais dos sujeitos da relação, apenas considerar a forma de execução da relação. É o objeto contratual que fixaria a relação de emprego e não seus sujeitos. Isto é, era a subordinação jurídica o objeto contratualmente negociado entre trabalhador e empregador e não 
mais a venda da força de trabalho. Se antes o Direito do Trabalho destinava-se aos hipossuficientes marcados pelo seu estado de assalariados, agora, somente interessam os assalariados que laboram sobre forte subordinação hierárquica e pessoal.

Esta ideia de subordinação seria melhor retratada com o verbete "sujeição", entendida como sujeito dependente do poder de outro. Mas o signo sujeição tem significante muito relacionado à sujeição do escravo, o que justifica sua não utilização pelo peso histórico que rememora, ou seja, “[...] poderia sugerir submissão do trabalhador, a recordar o estado de servidão a que se viu submetido o escravo em certas etapas da história humana" (ROMITA, 1979, p. 72). Tratava-se de uma mudança de filosofia idealista. Retira-se simbolicamente o nome de sujeição pessoal, mas esta alteração de nomenclatura nada modifica a realidade de sujeição pessoal. Isto porque não era conveniente ao capitalismo (ou a doutrina juslaboral) resgatar traços do trabalho forçado, mesmo que estes fossem os mais aproximados ao da nova realidade.

$\mathrm{Na}$ atualidade pós-fordista, as formas atípicas de trabalho - novas formas - são o sintoma maior da crise da subordinação. Um dos traços marcantes deste pós-fordismo que mais contribuiu para a formação destas situações atípicas é precisamente a tônica de colaboração e autonomia. Com as potencialidades de gestão e a possibilidade de controle na dispersão, a reengenharia produtiva não se vale mais do clássico padrão de trabalho apoiado nas relações de hierarquia-disciplina. No pós-fordismo, é possível visualizar outro cenário para o modo de trabalhar: não se exige a presença do trabalhador na sede da empresa; os serviços são determinados e até executados eletronicamente; a jornada não é fiscalizada, inclusive porque se prefere a remuneração por produtividade, a qual, pelo seu baixo valor, exige o máximo de trabalho, já impondo jornadas maiores, inclusive sem pagamento de horas extraordinárias; dispensa-se o poder punitivo ao repassar, por meio do expediente formal da falsa parceria, a posse (embora se diga que houve venda) da mercadoria a ser comercializada, fazendo com que a maior punição - não receber pelo trabalho prestado - ocorra quando a atividade não for realizada devidamente.

Estas novas estratégias de gestão da mão de obra sinalizam para a aparência de autonomia e independência, inclusive criando uma subjetividade capitalista de homem como empresa em desprestígio ao auto reconhecimentosubjetivo como trabalhador, conforme Cosentino (2018; p. 301) ou mesmo uma captura de subjetividade (ANDRADE; BEZERRA, 2017, p. 141). Presos a uma versão estreita e limitada do conceito de empregado como aquela jungida à subordinação pessoal e hierárquica, o dogmatismo não mais identifica o estado de dependência aonde ele sempre esteve. Com isso, operou-se a redução dogmática do campo de aplicação do Direito do Trabalho pela cegueira dogmática-jurisprudencial. 
Por outro lado, os problemas do critério da subordinação vinculam-se a uma tentativa de redução de custos através de estratégias gerenciais. Ao apenas visualizar o empregado como aquele que vive de ordens e teme punição, a doutrina juslaboral quase que, subliminarmente, estimulou a gestão de pessoal a, retirando este traço fundamental de ordens, eliminar também a proteção trabalhista. Isto é, a limitação jurídica do conceito de empregado propiciou o sucesso econômico da nova técnica de gestão de pessoal. A consequência prática é que a restrição do conceito de subordinação à tão somente subordinação pessoal e hierárquica produziu a exclusão da proteção aos assalariados que não são rigidamente hierarquizados.

Por isto, é preciso notar que a fuga da subordinação representa o ideal de lucro sem responsabilidade, confirmando a lógica capitalista de extração de mais riqueza mediante a redução dos custos. Logo, não pairam dúvidas de que o motivo principal do esvaziamento ou da própria crise da subordinação jurídica é justamente o interesse de evasão à proteção trabalhista, precisamente ao custo desta tutela legal. Não somente o discurso modista de formas novas de trabalho e de um novo perfil do trabalhador legitima a opção por uma contratação de força de trabalho "por fora" do marco regulatório do emprego. É antes uma decisão econômica - redução de custos como necessidade da intensa concorrência, inclusive com práticas sistêmicas de dumping social - que conduzem a criar novas modalidades de contratação, inclusive sob a lógica de colaboração e autonomia.

A insuficiência da subordinação jurídica se demonstra, porquanto seu sentido prevalecente e hegemônico (subordinação subjetiva) é a noção de subordinação pessoal ou hierárquica. Seu conteúdo corresponde essencialmente ao dueto ordem-punição, elementos externos pautados numa relação rigidamente hierárquica do empregador (superior) com o empregado (inferior). Ocorre que as dinâmicas contemporâneas de trabalho firmam-se, cada vez mais, numa relação aparente de colaboração, ruindo com a antiga rígida hierarquia. A contemporaneidade enfraquece o enunciador (ordens e fiscalização) para uma afirmação subliminar do enunciado (trabalho).

Antes mesmo das formas novas e das dinâmicas de autonomia, a concepção clássica da subordinação jurídica era, numa perspectiva crítica, incapaz de justificar situações distintas do tradicional trabalho operário-fabril. A subordinação clássica sempre teve dificuldades de abranger o trabalho intelectual ou especializado tecnicamente, tendo que, para estes tipos de trabalhadores, ser reformulada para uma subordinação "externa" e "tênue". Nestas situações, é preciso considerar a subordinação por "indícios externos", tal como respeito a horário de trabalho e necessidade de comparecimento na empresa (BARASSI, 1953, p. 411). No mesmo sentido, a noção clássica de subordinação não explica satisfatoriamente o trabalho a domicílio, inclusive 
porque, nestes casos, sequer pode valer-se da ideia de subordinação externa, pois não controla nem o tempo e nem o local da prestação dos serviços.

Ademais, a ideia de controle se manifesta igualmente em outras situações distintas daquela de trabalho dependente. Ou seja, afirma-se, cada vez mais, que o controle se realiza sem a clássica subordinação. Existe controle nos contratos de obra/resultado e estes, ainda assim, podem ser desenvolvidos sob o prisma da autonomia ou da dependência. Há controle nas terceirizações, conforme se constata numa leitura atenta destes contratos de apoio empresarial, notadamentequando as empresas prestadoras de serviços e seus empregados observam atentamente o padrão de trabalho e a cultura organizacional da tomadora. Nos contratos de franquia, ocorre a observância de um padrão minucioso de trabalho, caracterizando manifesta subordinação técnica e organizativa do franqueado para com seu franqueador. Logo, a sujeição à forte subordinação não se restringe ao trabalho dependente, o que demonstra que a subordinação não é algo exclusivo da relação de emprego.

Nestes termos, se a condição originária do Direito Laboral foi a proteção aos trabalhadores economicamente fracos e se a atual crise limita esta proteção ao contingente diminuto de pessoas, a perspectiva futura do Direito do Trabalho - caso queira permanecer com sua ontologia - é ampliar sua proteção para os demais hipossuficientes. Para tanto, é imprescindível superar a concepção de subordinação como sujeição hierárquica. Noutro sentido, as concepções renovadas de subordinação objetiva ${ }^{2}$ têm seus méritos, especialmente seu esforço em corrigir uma redução conceitual indevidamente realizada pela doutrina ao contentar-se com uma forte hierarquia. Todavia, continuam considerando uma consequência do fenômeno - a direção ampla subjacente à integração - como o próprio fenômeno do trabalho dependente.

A teoria da subordinação jurídica nunca rompeu a superficialidade da questão do estado de assalariado, justamente por creditar correção teórica à uma concepção insustentável epistemologicamente. A essência do assalariamento, como modelo capitalista de organização das relações de trabalho, não reside nos conceitos jurídicos, os quais somente visualizaram sua epiderme quando se vincularam à ideia de ordens (hierarquia) ou integração (acoplamento). É o mito da completude da ciência jurídica que legitima e impulsiona uma explicação apenas "jurídica" para a realidade social, ainda no afã irrefletido de uma "teoria pura", no caso para o Direito do Trabalho.

Diante da principal consequência do assalariamento - "receber ordens" - e ansiosa por

2 Em todas, realça-se o aspecto da integração do trabalho em detrimento ao aspecto da sujeição pessoal às ordens Cita-se a: subordinação estrutural de Maurício Delgado Godinho (2006); a subordinação estrutural-reticular de José Eduardo Chaves Junior e Marcus Menezes Barberino Mendes (2008); a subordinação integrativa de Lorena Porto (2009); a subordinação potencial de Danilo Gaspar (2011). 
rejeitar os "perigos" de uma concepção econômica de dependência, a doutrina encontrou seu "melhor" critério, passando a definir o empregado - expressão jurídica do assalariado - como aquele sujeito subordinado. À primeira vista, os assalariados ao venderem sua força de trabalho colocavam sua energia à disposição dos seus tomadores, aceitando, então, como necessidade técnica, a direção dos seus serviços. Logo, o conteúdo jurídico imediato da situação econômica de assalariado era estar "sob ordens".

No entanto, este primeiro cenário de disposição da força de trabalho se modifica sensivelmente nas situações de trabalho intelectual (ou domínio técnico) ou em domicílio. Nestas hipóteses, a principal consequência fica mitigada, "adelgaçada", "diluída" e "ténue". Assim, o local de trabalho ou fiscalização de horário de trabalho não servem como referência de comprovação da subordinação. Igualmente, o contexto pós-fordista implementa sistemas externalizantes de trabalho, fugindo também da versão clássica de estar "sob ordens". Assim, pode-se verificar novos e antigos assalariados não sujeitos à subordinação, demonstrando que esta não integra ao conceito de assalariamento.

O assalariado caracteriza-se por colocar a venda sua força de trabalho, ou seja, por dispor de sua energia em favor de outro. Se o traço marcante da relação de emprego é estar à disposição de outrem, derivam-se daí duas possibilidades: a primeira de comandar intensamente esta "disposição"; a segunda de apenas estabelecer o resultado deste trabalho à disposição, considerando que o próprio trabalhador tem as condições (técnicas, intelectuais ou materiais) de realizar seu ofício sem vigilância e fiscalização. Não obstante as duas possibilidades de "disposição", a subordinação somente visualiza a primeira acepção, apenas compreende a disposição como estrita obediência às ordens contínuas. Por decorrência, a subordinação deve ser vista como consequência da relação de emprego e não sua causa.

Pela sua gênese positivista ${ }^{3}$ e pela sua natureza de consequência possível, é urgente retirar do critério da subordinação jurídica o protagonismo da definição da relação de emprego. Ainda no aprofundamento destas questões, averigua-se que é infundada a caracterização do Direito do Trabalho como a regulação fordista do trabalho assalariado. Isto é, o Direito do Trabalho se constitui como o marco regulatório do trabalho assalariado na sociedade capitalista e não como a correspondência jurídica da dinâmica organizativa do fordismo. Com efeito, o instituto juslaboral impregnado de fordismo - e, no caso brasileiro, de positivismo - foi o critério da subordinação jurídica. O Direito do Trabalho não é, portanto, um produto do fordismo, nem

3 A hegemonia da teoria da subordinação jurídica é obra de um positivismo cientificista doutrinário, que rechaçou conceitos subjetivistas, apoiando-se na (pseudo) neutralidade e segurança de um conceito (dito) objetivo. O critério da subordinação jurídica é interpretação doutrinária e jurisprudencial de um dispositivo legal bem mais amplo que, literalmente, refere-se só a dependência (OLIVEIRA, 2009). 
sob o aspecto cronológico, nem sobre o aspecto ontológico, embora se possa qualificar a noção clássica de subordinação jurídica como um conceito jurídico delimitado pela realidade fordista. Assim, a opção pela subordinação jurídica, na sua acepção clássica, representou uma guinada reducionista do campo de incidência do Direito do Trabalho, a qual, indevidamente, limitou o conceito de dependência à situação de sujeição hierárquica. Disto, há que se perceber a subordinação jurídica não capta a noção integral de assalariamento, mas apenas as consequências deste fenômeno.

\section{ENTENDENDO O TRABALHO ASSALARIADO}

Fugindo do positivismo e da dogmática, é imperioso voltar a entender o que é trabalho assalariado para, então, repensar a proteção jurídica desta relação de trabalho. Na filosofia política, Jonh Locke (1978) atribui ao trabalho a fonte da propriedade. Pressupondo que o homem tem a propriedade de sua própria pessoa, terá, igualmente, a propriedade sobre os frutos do seu trabalho. É o trabalho da pessoa sobre os bens naturais, originalmente comuns a todos, que os coloca fora desta propriedade comum e dentro da propriedade individual. Em nome do trabalho realizado, a pessoa se apresenta perante a coletividade como proprietária, exigindo um direito natural à garantia desta propriedade pela sua justa origem no trabalho. Esta noção, impregnada de individualismo, pressupõe que a liberdade individual somente se concretiza quando o indivíduo é proprietário de si mesmo, sendo a sociedade o mercado de encontro entre estes proprietários.

Além de criar a propriedade, o trabalho também cria a riqueza. Rompendo com a crença fisiocrata de que a agricultura é a criadora da riqueza, Adam Smith (2010) credita a riqueza das nações não ao acúmulo de metais ou aos ganhos das trocas mas sim ao trabalho humano. Em grande medida, a riqueza cresce conforme a divisão do trabalho, que exerce a função de motor deste crescimento e que desenvolve os papéis dos indivíduos no sistema social. A divisão do trabalho se perfaz como tendência natural do desenvolvimento dos processos de troca, sendo, entretanto, dependente de uma acumulação de capital. A partir daquele considerado como pai da economia política, o trabalho é concebido como ideia abstrata que cria valor e, simultaneamente, como atividade concreta produtora dos homens.

No entanto, a estruturação social capitalista, notadamente a divisão da propriedade, não permitiu que os trabalhadores fossem os titulares do resultado do seu labor, como deveria ocorrer pela ideia de Jonh Locke. Descontados as despesas com os meios de produção (matéria-prima, instalações e instrumentos), a criação de riqueza se expressa na diferença entre o valor criado pela forçadetrabalho (produto apropriado pelo capitalista) e a remuneração paga a mesma 
forçadetrabalho. Isto porque o salário, em essência, não pode corresponder ao total do valor criado pelo trabalho, sob pena de não ser salário, mas uma retribuição integral do trabalho agregado, tal como numa legítima sociedade. Adam Smith já tinha percebido que o produto do trabalho não é somente do trabalhador. "[...] todo o produto do trabalho nem sempre pertence ao trabalhador. Ele deve, na maioria dos casos, dividi-lo com o proprietário do estoque, que o emprega" (SMITH, 2010, p. 44).

A riqueza social, então, é o produto do trabalho social, sendo apropriada, no bojo das relações salariais, pelos contratantes proprietários, na forma de mais-valia (trabalho excedente não pago). Karl Marx elucida a questão: "O modo capitalista de apropriar-se dos bens, decorrente do modo capitalista de produção, ou seja, a propriedade privada capitalista, é a primeira negação da propriedade privada individual, baseada no trabalho próprio"(MARX, 2006, p. 876-877). Vêse que nas relações de trabalho entre proprietários e não-proprietários, o primeiro se apropria dos valores produzidos pelo segundo, o que ocorre sob a aparência (ou pela ocultação) de livre contrato de trabalho com um salário "justo". A apropriação do valor se converte em (nova) propriedade: a propriedade das mercadorias produzidas pelos trabalhadores.

Despossuído de propriedades e possuído por prementes necessidades de subsistência, o trabalhador surge discursivamente como um sujeito livre, por não mais estar sob os grilhões da escravidão ou o pagamento sensorial da corveia na servidão. Robert Castel desvela: "O assalariado é então 'livre' para trabalhar, mas a partir do lugar que ocupa num sistema territorializado de dependência, e o trabalho que executa é exatamente o mesmo tipo do da corvéia" (CASTEL, 1998, p. 199). O capitalismo empreende um discurso de ampla liberdade de trabalho, que se estende da possibilidade de escolha do emprego ou mesmo da desistência deste a qualquer tempo. Entretanto, estrutura relações sociais, políticas, econômicas e tecnológicas que tecem fios invisíveis que limitam tais possibilidades, alocando, em regra, o trabalhador sempre na condição de dependente. Ao privar da substancial propriedade, impele sempre uma dependência do não-proprietário para com o proprietário, até porque a pobreza vicia a liberdade.

Uma real liberdade de trabalho corresponderia à liberdade de acesso aos meios de produção, não a situação de imperativo de sobrevivência que compele o trabalhador atrabalhar, de modo que a necessidade subjuga a vontade. A maioria das funções, na atual divisão social do trabalho, não são desejadas, mas aceitas por razões de necessidade e realizadas sem desejo, de modo insosso e desprezível. Em outras palavras, a separação dos meios de produção do trabalhador acarreta também em alienação/estranhamento e sub-alternatividade do trabalhador frente à mercadoria. $O$ estranhamento no trabalho remete a caracterização deste como mercadoria, talvez por isso seja chamado de "mão de obra". 


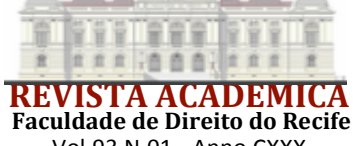

Voculdade de Direito do Recife

Vol.93 N.01 - Anno CXXX

Com isso, a situação objetiva de trabalhar para outrem já significa a subordinação formal deste que trabalha em favor daquele que recebe o trabalho. Esta subordinação cinge-se ao manifesto controle do tomador do serviço, através não da direção técnica, mas sim da detenção da propriedade dos meios de produzir. Nestas circunstâncias, o direito de propriedade na circulação capitalista empreende o papel de sonegar qualquer propriedade oriunda do trabalho para aquele é que não previamente proprietário, como o trabalhador. Portanto, o assalariado se caracteriza pela constante necessidade e dependência, pois somente possui sua força de trabalho. A coação ao trabalho se faz pela miséria e pela necessidade de obter meios para a sobrevivência ${ }^{4}$, embora esta condição de dependente esteja camuflada pela formatação jurídica de liberdade contratual oriunda de individualismo e formalismo jurídicos iluministas. Como reforço a esta dependência estrutural, visualiza-se, ainda, a situação dos desempregados que formam um exército industrial de reserva, o qual reitera a disputa pela condição de vendedor de força de trabalho.

A questão central do modelo capitalista é, portanto, o monopólio por uma classe social dos meios de produção, impelindo a classe não-proprietária a vender sua força de trabalho, inclusive com cessão de trabalho excedente. Diferentemente dos modos de produção anteriores que se pautavam em trabalho forçado (escravo, corveia, etc) através da atuação do poder do Estado -, o capitalismo construiu um modelo de trabalho formalmente livre, mas que, pela não detenção dos meios de produção, realiza-se como trabalho socialmente imposto. Se antes a coação era baseada na lei, agora ela ocorre pela própria estrutura social e, assim, de modo invisível.

Em síntese, a liberdade de trabalho dos não-proprietários num regime capitalista cria um estado estrutural de dependência do assalariado em face do capital, a despeito das garantias jurídicos-formais. A liberdade de trabalho do assalariado subjaz a necessidade imperiosa de sobrevivência, explicada pela perda anterior da titularidade dos meios de trabalho e reforçada pelo receio de prosseguir nas fileiras dos desempregados. Por fios invisíveis, estabelece-se uma dependência estrutural de um para com o outro, daquele que, como imperativo de sobrevivência, precisa imediata e cotidianamente vender-se ao outro, quer seja por não haver outra possibilidade econômica (ausência de propriedade), quer seja porque, em termos técnicos, não sabe

4 No lugar da coação legal ao trabalho, adota-se a coação pela fome e necessidade ao trabalho. "O velho paradigma do trabalho forçado não é pois recusado enquanto se constitui o embrião de uma condição de assalariado "moderna". Ao contrário, ele acompanha e tenta enquadrar seus primeiros desenvolvimentos. O que pode ser perfeitamente entendido: as condições de trabalho são tais nas primeiras concentrações industrias, que é preciso estar sob a mais extrema sujeição da necessidade para aceitar semelhantes "ofertas" de emprego, e os infortunados assim recrutados aspiram somente a deixar o mais rápido possível esses lugares de derrelição" (CASTEL, 1998, p. 206). 
desenvolver outro ofício senão aquela função parcelar-polivalente.

A produção dessa riqueza tem observado a lógica da intensificação do processo de trabalho, sendo esta a tônica do capitalismo ${ }^{5}$, ora pela extensão da jornada de trabalho, ora pelo aumento de produtividade oriundo das inovações técnicas e da divisão do trabalho, ou mesmo pela conjunção de ambas. Para obter mais produtividade no mesmo tempo, é necessária a intensificação do trabalho (obtenção de maior eficácia), seja pelo aumento da velocidade da máquina, seja pela cumulação da operação de máquinas para um único empregado, seja pela maior disciplina e controle para eliminar os "poros da jornada".

Precisamente, as diversas formas de organizar a produção (fordismo,toyotismo e uberização), com metodologias distintas, somente concretizam a lógica do capital de mais acumulação através da intensificação do trabalho. $\mathrm{O}$ diferencial do pós-fordismo não reside no avanço tecnológico, mas na relativa ruptura com o parcelamento das funções e com a implementação de uma lógica voraz de colaboração de classes. Como decorrência, o toyotismo foi economicamente bem sucedido porque conseguiu, pela sua sistemática de gerência produtiva, dar respostas satisfatórias (ganhos de produtividade e lucro) às oscilações contemporâneas do mercado (retração e expansão), além da incorporação da precariedade ao sistema produtivo. Já a uberização prossegue nesse caminho de precarização do trabalho, forjando uma aparência de contrato de parceria, apesar do dirigismo tecnológico e econômico, além da imposição dos riscos do negócio ao trabalhador.

Esta análise, pautada essencialmente na crítica de Karl Marx à economia política clássica, revela-se adequada para explicar as relações contemporâneas de trabalho no capitalismo. A compreensão dialética da totalidade do conjunto social permitiu a Marx identificar as estruturas gerais do trabalho assalariado e formular suas implicações, notadamente a ideia central: a dependência estrutural e prévia do assalariado ao empregador. Como consequência, o sujeito assalariado é aquele que, forjado no despossuimento, é impelido, embora juridicamente livre, a vender-se como mercadoria - como uma força - em troca do salário, cujo proveito econômico resultante deste trabalho é apropriado por outro. Despossuído, coagido e expropriado são termos delimitadores do conceito de trabalhador assalariado.

Agravando a dependência, os novos discursos da uberização tentam recolocar a situação de precariedade e instabilidade anterior ao próprio trabalhismo. No tempo presente, a principal consequência desta precariedade do trabalho tem sido o esvaziamento da forma clássica do

5 Nestes termos, Karl Marx anteviu os caracteres do fordismo e do toyotismo na recorrente dinâmica de intensificação do trabalho, descrevendo a lógica capitalista de intensificação do trabalho: Não existe a menor dúvida de que a tendência do capital, com a proibição definitiva de prolongar a jornada de trabalho, é compensarse com elevação sistemática do grau de intensidade do trabalho e de converter todo aperfeiçoamento da maquinaria em meio para absorver maior quantidade de força de trabalho (MARX, 2006, p. 476). 
emprego pelas diversas medidas de externalização e precarização. Talvez como resposta do capital a um certo status de proteção legal obtido na forma jurídica emprego ou mesmo apenas a renovação da lógica ontológica de extração de lucro, foram criadas novas formatações de nãoemprego para a prática de trabalho assalariado.

Assim, o cenário político-social do mercado de trabalho nacional assemelha-se a um grande mosaico, com figuras aparentemente dispares e antagônicas - assalariado protegido e precário, toyotismo e fordismo, flexibilização de relações já "flexíveis", trabalho escravo contemporâneo e automação - que se firmam como integrantes de uma mesma dinâmica. Sem prejuízo da singularidade histórica, a expansão do capitalismo - leia-se mais extração de riqueza do trabalho - realiza-se com mais intensidade e com mais enfraquecimento dos trabalhadores, o que lhes atribui uma condição estruturalmente mais dependente do Capital quando comparada aos países de capitalismo central. Por sinal, o verbete "dependente" desacompanhado de qualquer adjetivo é justamente o texto literal da definição legal de empregado, consoante art. $3^{\circ}$ da CLT. Todavia, o positivismo e seu afã puritano reduz, intencionalmente, esta dependência à subordinação jurídica.

O mercado de trabalho brasileiro, portanto, não é destinatário, em termos hegemônicos, da proteção do Direito do Trabalho. Conjuntamente com as questões sociais, políticas e históricas descritas acima, a conceituação de empregado adotada pelos operadores jurídicos tem uma parcela de responsabilidade nesta considerável ineficácia do Direito Laboral. Justamente a subordinação jurídica, precisamente sua vertente subjetiva, simboliza um acesso estreito e limitado para o mundo da tutela trabalhista. Como visto, esta "pequenina entrada" colabora significativamente para impedir que mais assalariados recebam a proteção social que o Estado brasileiro juridicamente se comprometeu.

\section{EM DEFESA DA DEPENDÊNCIA ECONÔMICA}

Diante dos problemas do conceito clássico da subordinação jurídica e das situações paradoxais de trabalho dependente não-subordinado, a dependência econômica tem sido novamente cogitada como nota distintiva do Direito do Trabalho. Por consequência, parcela da doutrina nacional e estrangeira cada vez mais se vale da antiga ideia de dependência como critério mais pertinente para o enfrentamento das situações atuais de trabalho. $\mathrm{O}$ critério, outrora renegado e tido como inaceitável pelo seu conteúdo extrajurídico, desponta novamente no debate doutrinário.

No horizonte estrangeiro, o debate está franqueado, tendo a dependência econômica um lugar de destaque como alternativa ou complemento à subordinação jurídica. As novas figuras 
atípicas nas relações de trabalho são todas envoltas pelo estado de dependência econômica que é de difícil enquadramento na clássica subordinação. O professor português José João Abrantes (2004, p. 94-95) enuncia que: na Itália a legislação valeu-se do epíteto "parassubordinado" ( $i l$ lavoro parasubordinato); na Alemanha designa-se "pessoas semelhantes a trabalhadores" (arbeitnehmeräh nliche persone) ${ }^{6}$, pois são prestadores de serviço economicamente dependentes (tarifsvertragsgesetz), também intitulados quase-trabalhadores; em Portugal, denomina-se contratos equiparados.

No espectro da Organização Internacional do Trabalho - OIT, discute-se o problema do conceito de empregado e o seu campo de destinatários. No debate da $91^{\mathrm{a}}$ Reunião da OIT em $2003^{7}$, enfrentou-se a questão do "ámbito de larelación de trabajo" e, por consequência, as situações de "trabajo encubiertas o ambiguas". No relatório do debate, afirma-se que "La dependencia económica, es cierto, no entrañasubordinaciónen todos los casos, pero puede ser uncriterio útil para determinar si untrabajador es unasalariado y no unempleado por cuentapropria" (OIT, 2010, p. 31-32).

A condição de dependente do trabalhador é indiscutivelmente a causa e a razão de ser do Direito do Trabalho. Com efeito, é o traço da dependência o constitutivo da singularidade do juslaboralismo, haja vista que seu caráter protetivo, limitador da exploração deste trabalho, é o caractere que o distingue das demais disciplinas das relações privadas. Serve, então, como medida de garantia de civilidade a uma relação econômica que é estruturalmente injusta e desproporcional. O Direito do Trabalho destina-se aqueles que somente têm a força de trabalho como possibilidade de vida e, assim, como serem dependentes daqueles que lhes ofertem um salário.

A justificação histórica e ontológica da criação de uma tutela legal para as relações de trabalho é a condição essencialmente dependente do trabalhador assalariado para com o Capital. Por esta razão, o critério da dependência econômica detém uma força histórica marcante no Direito do Trabalho, como delimitação conceitual jurídica da condição de assalariado. Apesar dessa importância histórica e ontológica, entendeu-se que a dependência econômica era tão somente a causa "pré-jurídica", nada além disto. Estando fora da seara jurídica, não poderia, então, servir como critério jurídico, sob pena de ofensa ao puritanismo conceitual positivista. Há

6 O "assemelhado ao empregado" do direito alemão é mais um exemplo do retorno à dependência econômica. "Impressiva, em tais prestadores-colaboradores, é a marca da dependência econômica que os acaba por conduzir a uma situação fática de equivalente à relação de emprego, o que é enfaticamente ressaltado por Wollenschläger, quando define o assemelhado como aquele que frequentemente se encontra em situação de carência econômica tal qual o empregado tutelado" (VILHENA, 2005, p. 545-546).

7 Na mesma trilha, a Recomendação 198 da OIT afirma o objetivo de tornar claras as definições em cada legislação nacional dos critérios de reconhecimento do vínculo de emprego, visando assegurar a proteção legal contra situações de trabalho "encubierto". 
inexplicável paradoxo nesta rejeição de importância e utilidade.

Da história e da ontologia, confirma-se que a tutela do trabalho sempre foi legitimada socialmente pela condição hipossuficiente do trabalhador. E a medida desta hipossuficiência - de quem trabalhar para outrem - é justamente a dependência econômica. É a razão histórica e ontológica que justifica e legitima o modelo de proteção do Direito do Trabalho em favor daquele sujeito não-proprietário que vende sua força de trabalho, pela sua prévia condição de dependente econômico.

A retomada da dependência econômica para que seja mais efetiva deve ser (re)pensada numa dimensão mais aprofundada em relação aquela ideia apresentada no início do século XX O perfil daquele sujeito que vive da venda do seu trabalho seria a primeira tradução jurídica para o conceito de dependência econômica. $\mathrm{O}$ primeiro autor a usar o conceito de dependência foi o francês Paul Cuche em 1913, para o qual a dependência econômica decorria de dois requisitos inseparáveis. Primeiro, o trabalho deverá ser a única ou principal fonte de sobrevivência do trabalhador, conferindo ao serviço prestado a condição para o seu sustento. Segundo, o empregador deve absorver de forma regular e integral os serviços prestados pelo trabalhador, havendo, portanto, a inserção e exclusividade do trabalho deste na empresa. Em síntese, o trabalho do obreiro lhe garantiria prevalentemente sua subsistência e seria exclusivo em favor de um tomador.

Um outro autor francês, Alexandre Zinguerevitch, formulou um conceito mais amplo de contrato de trabalho, a partir dos traços mais gerais da dependência econômica, enfocando especialmente a questão da privação da liberdade econômica. Zinguerevitch pretendia defender uma noção ampla de contrato de trabalho a partir dos critérios gerais da OIT, em especial o princípio diretor de que o trabalho não pode ser tratado como mercadoria, quebrando ou limitando juridicamente o "livre jogo" da lei de oferta e procura de mão de obra no mercado de trabalho.

O pressuposto de Zinguerevitch era "[...] o que caracteriza essencialmente as relações entre o patrão e o empregado é estado de fraqueza e dependência econômica no qual se encontra o segundo em relação ao primeiro" (1936, p. 28). Logo, quem não pode trabalhar para si mesmo e, assim, precisa fornecer seu trabalho para outro é economicamente fraco. Seriam, então, dependentes aqueles sujeitos "privados de liberdade econômica". Como resposta às críticas, muitos autores aderiram à justaposição da dependência econômica à subordinação jurídica. Cabe notar que o próprio Paul Cuchese referia à dependência econômica como um critério adicional à subordinação jurídica.

Como visto, a delimitação jurídica do critério da dependência econômica sempre se 
ateve à superficialidade quando concebe o dependente como sendo aquele trabalhador que vive da remuneração. Este viver de salário representa apenas a epiderme do fenômeno, haja vista que todos os que prestam serviços, inclusive os autônomos, vivem da contraprestação pecuniária recebida. De igual modo, empresas podem se encontrar em uma situação de dependência econômica para com outras empresas maiores, a exemplo dos processos produtivos de subcontratação.

Como reparo a esta superficialidade, José Martins Catharino já esboçava uma acepção relativizada da dependência econômica, visando torná-la mais juridicamente eficaz. "Na sua concepção relativa, [...] bastando que o salário seja o principal meio de vida, e a absorção parcial e predominante do seu tempo disponível por empregador" (CATHARINO, 1982, p. 203). O mesmo autor destaca adiante que ainda assim há falha no critério, invocando a hipótese fática em que uma pessoa trabalhe e seja igualmente remunerada por duas empresas. Entretanto, o professor baiano frisa que a ausência de dependência econômica, ou seja, uma situação de independência econômica do obreiro, é manifestação clara da desfiguração do contrato de emprego. Catharino registra que as divergências com a ideia da dependência econômica não resultam sua invalidade, graças a sua sólida raiz histórica e política do critério que lhes garantem sustentação (1982, p. 204).

Atrelada à aparência primária da dependência econômica, a doutrina juslaboral teceu diversas críticas a este critério, concluindo pela sua imprestabilidade. A primeira negativa à dependência econômica provém do seu caráter extrajurídico ${ }^{8}$, que corresponde a um demérito, pois o conceito não foi formulado nos precisos e completos marcos conceituais do direito. Além do equívoco epistemológico advindo do positivismo que sustenta esta crítica à extra-juridicidade, há uma pretensão subliminar de completude do sistema jurídico que, assim, não pode admitir critérios que não sejam autossuficientes no próprio direito.

A crítica relativa à exclusividade é infundada, eis que se apresenta como uma consequência superficial do fenômeno. Quem vive de salário deve, por suas necessidades vitais, buscar o número máximo possível de tomadores, a fim de garantir sua sobrevivência. A necessidade de vender-se a mais de uma empresa é, ao contrário, reforço da debilidade econômica do trabalhador que não consegue encontrar os meios de subsistência satisfatória em

8 A crítica de Orlando Gomes e Elson Gottschalk é forte contra o extrajurídico. Afirmam que "[...] padecem do mesmo vício de origem [a dependência econômica e dependência social]. Pretendem caracterizar um contrato com elementos metajurídicos. $\mathrm{O}$ erro de seus defensores provém de procurarem, preferentemente, analisar a condição social e econômica do trabalhador, em vez de examinar a relação jurídica da qual ele participa. [...] $\mathrm{O}$ equívoco dos que adotam critérios extrajurídicos reside exatamente no fato de se não preocuparem com a fixação do elemento característico do contrato de trabalho, mas sim com a qualidade da pessoa que deve ser protegida" (GOMES; GOTTSCHALK, 2005, p. 141). 
um único empregador, quando the é fisicamente possível trabalhar para diversos tomadores. Note-se que este é o exemplo sintomático do avulso que precisa necessariamente de diversos tomadores para realizar sua sobrevivência.

Todas as críticas acima foram responsáveis para a rejeição do critério da dependência econômica como nota distintiva da relação empregatícia. Embora seja pacífico que a dependência é a causa,urge, portanto, transpor esta visão epidérmica, para começar entender com profundidade interdisciplinar a noção de trabalho dependente.

\section{TRABALHO DEPENDENTE E UBERIZAÇÃO}

Se a dependência econômica tem sido, até então, enfrentada sobre seus aspectos superficiais e igualmente criticada pelos problemas oriundos desta aparência, é premente romper com esta análise epidérmica. $\mathrm{O}$ aprofundamento da noção dependência implica refazer, agora com o esteio numa compreensão interdisciplinar e crítica, uma delimitação jurídica do trabalho assalariado. Almeja-se resgatar a sinonímia integral entre trabalhador assalariado e trabalhador dependente.

O primeiro elemento desta delimitação jurídica é reconhecer que o poder - e sua consequência potencial de subordinar os trabalhadores - de uma empresa capitalista decorre da sua propriedade. Retomando Karl Marx (2006, p. 385), vê-se que "O capitalista não é capitalista por ser dirigente industrial, mas ele tem o comando industrial porque é capitalista”. O capitalista comanda a empresa em nome da propriedade de que é titular. Por ser o sujeito proprietário, podese afirmar como o comandante da empresa. Por decorrência, o poder diretivo é mera consequência da produção capitalista e não sua qualidade distintiva.

O fundamento central da relação de trabalho é a propriedade, precisamente porque o caráter singular desta relação é o intercâmbio entre proprietários e não-proprietários. Entretanto, essa questão é ocultada no Direito do Trabalho. A ênfase que o juslaboralismo confere ao poder diretivo atua, de certa medida, como ocultadora e naturalizadora desta relação entre proprietário e não-proprietário 9 . O contrato de trabalho aparece, então, como o momento jurídico de legitimação da subordinação, embora antes mesmo de contratar, o trabalhador já é dependente por não ser proprietário.

9 O jovem Orlando Gomes, conjugando as contribuições de La Cueva e Sinzeheimer, aponta que o direito de propriedade funda uma situação de poder do empregador sobre o empregado. Convém reproduzir o elucidativo trecho: "É fato incontroverso que a propriedade não confere apenas um poder sobre as coisas, mas, também, sobre os homens. Nos domínios da produção de riqueza, esse poder do proprietário concretiza-se, juridicamente, em um conjunto de faculdades através de cujo exercício faz sentir sua autoridade sobre os trabalhadores, isto é, sobre os homens que, não podendo ser proprietário de meios de produção, põem, à disposição dos que podem, a sua força-trabalho" (GOMES, 1944, p. 119). 
Sendo o assalariado um sujeito despossuído - por ausência de propriedade capaz de lhe permitir atuar como empreendedor - fica "livremente" impelido a vender sua força de trabalho. O despossuimento é que demarca sua condição de dependente e não o fato de depender de salário. A relação de dependência do assalariado para com a empresa é prévia ao contrato de trabalho e estrutural na sociedade capitalista, na medida em que a força de trabalho somente se realiza quando vendida ao Capital. Seu destino dirige-se estruturalmente à alienação em favor do empregador sob a condução sutil dos fios invisíveis da teia capitalista. O trabalho desconectado da propriedade no mundo capitalista reduz o sujeito trabalhador a apenas força de trabalho, ou seja, a algo a ser vendido como mercadoria em troca de salário. Infere-se aí que o viver do salário é a consequência do ser despossuído e não a própria condição de dependente.

Infere-se que, no capitalismo, o homem trabalhador não mais vende mercadoria (produto do trabalho), mas é a sua força que é comercializada. Dissocia-se, com evidência, o feitor do trabalho e o proprietário do resultado, situação que até então era coligada. O autônomo é aquele que é proprietário da matéria-prima e do resultado do trabalho, sendo que nele foi empregado sua força. Assim, o autônomo tem liberdade para quem vender e não somente se vincula a um único tomador. Aqueles que têm capital razoável para instituir e dirigir sozinhos sua empresa, mas que preferem seguir certos modelos de parceria (franquias, contratos de prestação de serviços, parceiros capitalizados, entre outros) são, por opção, sócios do capital, não sendo dependentes econômicos. É a esta a distinção da dependência econômica com a subordinação objetiva que incluiria estas pessoas integradas a um processo produtivo.

Tudo isto leva a compreender o sujeito assalariado como sinônimo total de sujeito dependente, como aquele tem seu trabalho apropriado pela empresa. Encontra-se o sujeito dependente como o ser despossuído e coagido a se vender como apenas mercadoria (força de trabalho). Neste particular, a subordinação jurídica em nada capta a questão do assalariado e sua pseudo liberdade. A dependência econômica, então, engloba a subordinação jurídica, sendo muito mais ampla do que esta, uma vez que considerando os elementos prévios do assalariado pode também considerar o trabalhador subordinado normalmente como dependente. $\mathrm{O}$ trabalho por conta alheia implica estado de dependência do trabalhador, a qual é "uma consequência ou um efeito da prestação de trabalho para terceiros, pertencerem originariamente a pessoa distinta da que efetivamente trabalha, esta se reserva um poder de direção ou de controle sobre os resultados [...]" (OLEA, 1969, p. 32).

O esqueleto geral do assalariamento é a relação de trabalho entre um proprietário e outro não-proprietário, na qual há uma dependência estrutural e prévia do segundo para com o primeiro. É esta dependência prévia a tônica do regime do assalariamento, pois quem vende 
trabalho e não mercadoria (vendida somente pelo proprietário) é assalariado. Quem vende trabalho é sempre subsumido ao seu comprador, pois vende algo que, por ser uma parte de um produto qualquer, somente se concretiza quando for vendida, isto é, quando colocada em ação na produção. A venda de trabalho (força de trabalho) é, assim, sempre dependente no capitalismo.

Percebendo a dependência como prévia, estrutural e distinta de pobreza, cumpre firmar sua delimitação conceitual não mais pelas consequências do fenômeno do trabalho assalariado como fez parcialmente a teoria da subordinação jurídica. Sabe-se que as definições construídas sobre as consequências dos fenômenos tendem a não captar a sua inteireza, como também a se esvaziar quando o mesmo fenômeno alterna seus efeitos. São estes os exemplos dos diversos critérios que atuaram como notas distintivas do Direito do Trabalho, eis que todos captavam apenas uma consequência parcial do assalariamento e logo se tornavam inadequados. A dependência técnica não se adequa ao empregado com domínio técnico, a sujeição hierárquica não combina com o trabalho intelectual, a vigilância e fiscalização têm dificuldades de materialização no trabalho a domicílio, a pobreza individual não explica a ocorrência de altos e médios assalariados e, por fim, a integração à empresa comporta, além dos assalariados, os autônomos. Em todos estes casos, a ênfase foi na consequência e não na causa.

O sentido da expressão "venda de força de trabalho" refere-se ao bem cuja utilidade econômica é restrita, por depender do seu acoplamento a um empreendimento, mais precisamente pela sua conjunção com a propriedade (meios de produção). Sendo o trabalho um dos elementos da empresa, seu destino é o de estar contido nesta. O trabalho dissociado da propriedade não pode agir como empresa; somente lhe cabe retornar a empresa pela "venda compulsória de força de trabalho". Ao contrário, quando o trabalho se encontra associado à propriedade seu resultado deixa de ser apenas força de trabalho (valor-de-uso) e passa a ser uma real mercadoria (valor-de-troca), recebendo os epítetos jurídicos de produto ou serviço.

A par disto, o termo "dependente" deve ser compreendido menos como um adjetivo (subordinado e assujeitado) e mais como aquele que predica ação "depender". O verbo “depender" - ação daquele que é dependente - deve privilegiar a semântica de "pertencer", "estar condido" e "fazer parte" em detrimento da subordinação advinda do "estar sujeito" ou carecer economicamente (HOUAISS, 2009, p. 616). O empregado é dependente porque sua força de trabalho não se realiza sozinha, pois pertence estruturalmente à empresa, fazendo parte desta e, como consequência possível, podendo ser subordinado.

A demarcação da dependência foi feita, até aqui, sem adjetivos, numa concepção generalizante. A chave da compreensão crítica da dependência é, então, seu conteúdo econômico, como correlato à ausência de propriedade. Trata-se da percepção de que esta forma de trabalho 
dependente é estruturada pelas condições econômicas da sociedade capitalista. Em nome da propriedade, coage-se ao trabalho, como também, por força da propriedade, expropria-se a riqueza criada pelo trabalhador. Não é à toa que o centro do capitalismo converge à propriedade e não ao trabalho, embora seja o trabalho fundador da riqueza que se represa em propriedade.

Qualificar a dependência como econômica significa explicitar a natureza capitalista da venda da força de trabalho e seu consequente Direito capitalista do Trabalho, que na fuga conveniente do extrajurídico termina esquecendo suas imbricações econômicas. Almeja-se destacar que a manifestação concreta de vontade e a liberdade, no capitalismo, pressupõe um sujeito proprietário, sendo remanescente a coação e a restrição da vontade para os nãoproprietários. Daí, resta impraticável considerar como contratantes iguais na sua livre vontade negocial o empregado e o empregador, nas recorrentes tendências flexibilizantes de retorno da convalidação da autonomia privada.

As disrupções ocasionadas pelas inovações tecnológicas e organizativas vêm quebrando a conexão entre o Direito do Trabalho e trabalhadores que vendem sua força de trabalho via plataformas digitais. Visualiza-se trabalhadores que vivenciam a condição econômica de assalariamento e experimentam uma dimensão de liberdade para decidir quando e quanto tempo trabalhar. Pelo olhar tradicional da lente fordista e sua concepção clássica de subordinação jurídica, é difícil aplicar a tais trabalhadores o regime legal trabalhista por esses descompassos.

No caso das plataformas digitais de trabalho, especialmente no modelo Uber, a propaganda de liberdade do trabalhador para definir quando se ativar e quando se desativar da plataforma é o argumento principal das decisões judiciais que declaram que ali há trabalhado autônomo. No entanto, a questão da definição do momento início ou mesmo de término do labor é superada pela "programação por controle" neste novo estágio de organização da empresa, o que pode ser entendido também como uma subordinação para além do chão de fábrica agora virtual por meios de controle onipresentes via revolução informacional (ANDRADE; BEZERRA, 2017, p. 126).

A visão da totalidade do algoritmo permite estimular ativações ou não desativações dos trabalhadores com propagandas e premiações. Conforme anota Pires, há expresso controle e direção dos serviços oferecidos no trabalho da plataforma Uber:

[...] as plataformas exercem significativa ingerência sobre elementos essenciais referentes às condições de pactuação e à forma de execução do serviço de transporte, procedimento que não se compatibiliza com a posição de mera intermediadora, que, no campo da formalidade, pretende sustentar. São as empresas que fixam o preço a ser cobrado pelas corridas, a forma de cálculo, a taxa a ser retida, as condições do veículo utilizado, os requisitos de cadastramento, as partes que serão conectadas, o trajeto a ser percorrido e, até mesmo, o comportamento que deve ser adotado pelo motorista durante 
Por outro lado, o poder disciplinar também é evidente. Inicialmente, pode a Uber suspender os motoristas, numa punição branda. Adiante, a Uber pode, de modo unilateral, excluir o motorista da plataforma, numa punição à semelhança de justa causa. Daí há que se reconhecer que a dimensão de real liberdade dos trabalhadores destas plataformas em comento é muito diminuta.

Justamente o algoritmo é o elemento organizacional que impõe controle e igualmente a dependência econômica do trabalhador. É traço caraterístico da Uber a utilização de um algoritmo que monitora as demandas, cruza os dados de oferta e procura, eleva os preços e desloca motoristas para atender aos preços majorados, além de avaliar os motoristas (OITAVEN; CASAGRANDE; CARELLI, 2018, p. 19). Com isso, cria uma "lei de mercado virtual" claramente dirigida a lhe favorecer com o chamado "preço dinâmico".

A mudança unilateral da política de preços das tarifas e da retenção da parte da Uber é indicativa de uma forte direção dos serviços e por outro lado de uma situação de vulnerabilidade por parte do motorista que não tem as condições econômicas ou jurídicas de resistir e de exigir equivalência das prestações contratuais.

O algoritmo concede pequenos espaços de autonomia, mas sempre numa trama de controle e direção da atividade empresarial. O preço baixo impele o reiterado desejo/necessidade de estar disponível para mais dias e muito mais horas de trabalho.

Guy Davidov (2016, p. 8-9), então, reabilita o critério da dependência econômica, sugerindo que os trabalhadores em estado de dependência, ainda que sem subordinação, sejam destinatários da proteção trabalhista, naquilo que considera como interpretação finalística do Direito do Trabalho. Isto porque considera que o algoritmo da Uber monitora seus motoristas e o controle destes é feito pelo sistema de classificação, enfatizando que os serviços são prestados em nome da Uber, indicando que o motorista se insere na organização empresarial da plataforma de transporte.

Por outro lado, o estudo empírico de Emilly Guendelsberger detectou que, em termos percentuais, a Uber cobra em média $28 \%$ do valor das corridas e que as despesas de operação veículo correspondem a 19\%. Por consequência, um motorista de Uber americano recebe uma média líquida de $\$ 9$ por hora de trabalho, percentual muito próximo a um trabalhador que recebe um mínimo americano e muitas vezes inferior ao salário mínimo de um taxista (SLEE, 2017, p. 118).

Na decisão da $33^{\mathrm{a}}$ Vara do Trabalho de Belo Horizonte, há uma insinuação de uma 
dimensão de dependência econômica. A sentença identifica que, após a análise econômica dos custos e despesas da prestação dos serviços, haveria intensa exploração de mão de obra pela Uber:

Sua força de trabalho pertencia à organização produtiva alheia, pois enquanto a ré exigia de 20 a $25 \%$ sobre o faturamento bruto alcançado, ao autor restavam as despesas com combustível, manutenção, depreciação do veículo, multas, avarias, lavagem, água e impostos. Tal circunstância evidencia que o autor não alienava o resultado (consequente), mas o próprio trabalho (antecedente), ratificando, assim, a dependência própria do regime de emprego. (BRASIL, 2017, p. 28).

No conhecido caso da decisão inglesa que reconheceu o vínculo empregatício dos motoristas da Uber, o traço da dependência econômica foi de considerável importância para essa conclusão.

A questão do preço imposto pela Uber é forte evidência de que a plataforma não é apenas uma intermediadora entre motorista e passageiro. Se fosse meramente intermediadora, não poderia nunca impor preços, pois quem media não estabelece o valor do trabalho alheio. Como a Uber estabelece os padrões remuneratórios, ela exerce direção econômica da atividade sob o trabalhador, sujeitando-lhe a uma dependência igualmente econômica.

No polo oposto, numa autonomia, notadamente de caráter econômico, caberia ao trabalhador independente estabelecer, como manifestação da sua autonomia e titularidade sobre sua força de trabalho, o valor do seu trabalho. Tal qual um empresário que fixa os valores dos seus produtos ou serviços, o verdadeiro trabalhador autônomo tem como atributo a capacidade de fixar o valor dos seus serviços, exceto no caso em que o próprio Estado, via medidas normativas, impõe uma tarifa pública para o serviço como ocorre no táxi. O preço fixado pelo UBER é manifestação clara de assalariamento, ou seja, trabalho sob dependência.

Daí conclui-se que há, no plano fático e na estrutura organizacional tecnológica desta atividade econômica, uma dependência total do trabalhador em relação aos sistemas de plataforma, no qual o trabalho somente se realiza naqueles padrões. E dada a expansão e monopólio das plataformas, a dependência no sentido de "fazer parte" é indiscutível, pois não há outro meio de trabalhar nesta atividade.

No caso particular do UBER, há controle por resultados pela mediação algorítmica e sem responsabilização trabalhista. Trata-se do retorno ao passado da total precariedade, no qual os trabalhadores que não organizam a atividade econômica, correm todo o risco do negócio e não auferem os lucros da sua atividade. Somente esta contextualização de exploração desregulada do trabalho justificaria - como já justificou na história do Século XVIII - a criação da proteção trabalhista para os estes trabalhadores hipossuficientes. 


\section{CONCLUSÕES}

No retorno interdisciplinar à compreensão do sujeito assalariado, rememora-se que a liberdade de trabalho proclamada nos discursos jurídicos é corroída pela realidade de necessidade que impele estes assalariados, como única opção, a vender-se como mão de obra. Seja no fordismo, toyotismoou na uberização, mantém-se o processo de intensificação do trabalho assalariado, em reforço da condição dependente do trabalhador, inclusive com a vertente de dependência consentida pela lógica da colaboração.

A dependência econômica, na sua dimensão ressignificada, apresenta-se como a caracterização do trabalhador como o sujeito despossuído, coagido e expropriado. Por não possuir propriedade substancial - o que não significa pobreza individual -, é conduzido a vender de sua força de trabalho como simples valor-de-uso, quando poderia, caso tivesse propriedade, vendê-la como valor-de-troca. Sendo obrigado a se vender, assume socialmente uma posição de assujeitado ao poder daquele que pode lhe comprar, inclusive dirigindo-o ou não. Por fim, a riqueza que se produz neste trabalho - o valor agregado - não lhe pertence, eis que, juridicamente, é a propriedade originária do empregador, apesar de pressupor uma propriedade prévia.

Afirmar a dependência como econômica demarca o aspecto econômico da relação, oriundo do poder que a propriedade confere ao seu titular. Destina-se a frisar que o Direito do Trabalho é, essencialmente, o Direito capitalista do Trabalho, o qual ao mesmo tempo que confere uma civilidade à expropriação do trabalho dos não-proprietários prossegue mantendo esta relação estruturalmente de expropriação.

Como visto, o modelo Uber é mais do que uma forma de organizar uma empresa, essencialmente um modelo de negócio com uma concepção sistêmica de atividade econômica baseado em tecnologia e com custos mínimos e, noutro ângulo, como intensa precarização das condições do trabalhador. Um dos fatores de sucesso econômico das plataformas de serviço ou trabalho é atuarem numa clara zona de desregulação, sob a aparente forma de plataforma de comunicação, imputando aos seus trabalhadores a forma de parceiros e autônomos. Agrava ainda mais essa situação de precariedade, a transferência dos riscos da atividade para os trabalhadores, sendo estes responsáveis pela aquisição e manutenção dos veículos, despesas de combustível, impostos sobre o veículo, seguro por acidente, além de outros, sofrendo ainda os riscos e o custo econômico da ociosidade, visto que estão disponíveis para trabalhar e não receber pelo tempo à disposição.

Como a Uber estabelece os padrões remuneratórios, ela exerce direção econômica da 
atividade sob o trabalhador, sujeitando-lhe a uma dependência igualmente econômica. No polo oposto, numa autonomia, notadamente de caráter econômico, caberia ao trabalhador independente estabelecer, como manifestação da sua autonomia e titularidade sobre sua força de trabalho, o valor do seu labor.

Com isso, o modelo de controle de certas plataformas digitais recoloca em crise o conceito tradicional de subordinação jurídica, todavia visualiza-se ali uma cristalina dependência econômica daqueles trabalhadores "parceiros". Daí que a procura pelos trejeitos antigos da subordinação fordista mostra-se inócua e naturalizadora do desguardo do trabalho eletronicamente assalariado.

\section{REFERÊNCIAS}

ABRANTES, José João. Estudo sobre o Código do Trabalho. Coimbra, Coimbra Ed, 2004.

ANDRADE, Everaldo Gaspar; BEZERRA, Zelia Costa Santos. ASPECTOS DA SUBORDINAÇÃO NO DIREITO DO TRABALHO. Suas implicações no contexto das novas tecnologias da comunicação e da informação. Revista Acadêmica da Faculdade de Direito do Recife, [S.1.], v. 89, n. 01, p. 125-143, out. 2017. Disponível em: https://periodicos.ufpe.br/revistas/ACADEMICA/article/view/109916. Acesso em: 09 nov. 2020.

BARASSI, Ludovico. Tratado delDerechodelTrabajo. Tomo I. Trad. Miguel Sussimi. Buenos Aires: Editorial Alfa, 1953.

BRASIL. 12 ${ }^{\mathrm{a}}$ Vara do Trabalho de Belo Horizonte. Sentença no processo $\mathbf{n}^{\mathbf{0}} 0010497-$ 38.2017.5.03.0012. Belo Horizonte, 2017.

CATHARINO, José Martins. Compêndio de Direito do Trabalho. v.1,São Paulo: Saraiva, 1982.

CASTEL, Robert. As metamorfoses da questão salarial: uma crônica do salário. 6.ed. Petropólis: Vozes, 1998.

COSENTINO, Carlo. Direito do trabalho, tecnologias da informação e da comunicação: impactos nas relações individuais, sindicais e internacionais de trabalho. Belo Horizonte: RTM, 2018.

DAVIDOV, Guy. The Status ofUber Drivers: APurposive Approach. Spanish Labour Law AndEmploymentRelationsJournal, [s.1.], v. 6, n. 1-2, p.6-15, 6 nov. 2017. Universidad Carlos III de Madrid. http://dx.doi.org/10.20318/sllerj.2017.3921. Disponível em: https://erevistas.uc3m.es/index.php/SLLERJ/article/view/3921. Acesso em: 21 fev. 2021.

DELGADO, Maurício Godinho. Direitos fundamentais na relação de trabalho. Revista LTr, São Paulo:LTr, ano 70, n. 6, p. 657-667, jun. 2006.

GASPAR, Danilo. A crise da subordinação jurídica clássica enquanto elemento definidor da relação de emprego e a proposta da subordinação potencial. 2011. Dissertação(Mestrado em Direito) Universidade Federal da Bahia. Salvador, 2011. 
GOMES, Orlando. Introdução do Direito do Trabalho.Rio de Janeiro: Revista Forense, 1944.

GOMES, Orlando; GOTTSCHALK, Élson. Curso de Direito do Trabalho. 17. ed. Atualizada por José Augusto Rodrigues Pinto e Otávio Augusto Reis de Sousa. Rio de Janeiro: Forense, 2005.

HOUAISS, Antônio. Dicionário Houaiss da Língua Portuguesa. São Paulo: Objetiva, 2009.

LOCKE, Jonh. Segundo Tratado sobre o Governo. InOs pensadores. Trad. AnoarAiex e E. Jacy Monteiro. 2. ed. São Paulo: Abril Cultural, 1978.

MARX, Karl. O Capital: crítica da economia política. Trad. Reginaldo Sant'anna. 24. ed. Rio de Janeiro: Civilização brasileira, 2006. Livro I, v. 1.

MARX, KarlO Capital: crítica da economia política. Trad. Reginaldo Sant'anna. 23. ed. Rio de Janeiro: Civilização brasileira, 2006. Livro I, v. 2.

MENDES, Marcus Barberino; CHAVES JUNIOR, José Eduardo de Resende. Subordinação estruturalreticular: uma perspectiva sobre a segurança jurídica. Disponível em :http://www.trt3.jus.br/escola/download/revista/rev_76/Marcus_Jose.pdf. Acesso em: 01 dez. 2008.

OITAVEN, Juliana; CARELLI, Rodrigo; CASAGRANDE, Cássio Luís. Empresas de transporte, plataformas digitais e a relação de emprego: um estudo do trabalho subordinado sob aplicativos. Brasília: Ministério Público do Trabalho, 2018.

OLEA, Manoel Alonso. Introdução ao Direito do Trabalho. 2. ed. Porto Alegre: Sulina, 1969.

OLIVEIRA, Murilo Carvalho Sampaio. (Re)Pensando o Princípio da Proteção na

Contemporaneidade. São Paulo: LTr, 2009.

ORGANIZAÇÃO INTERNACIONAL DO TRABALHO (OIT). El ámbito de larelación de trabajo. Disponível em:http://www.oit.org/public/spanish/standards/relm/ilc/ilc91/pdf/rep-v.pdf. Acesso em 30 nov. 2010.

PIRES, Elisa Guimarães Brandão. Aplicativos de transporte e o controle por algoritmos: repensando o pressuposto da subordinação jurídica. 2019. Dissertação (mestrado) - Universidade Federal de Minas Gerais, Faculdade de Direito: Belo Horizonte, 2019.

PORTO, Lorena Vasconcelos. A subordinação no contrato de trabalho: uma releitura necessária. São Paulo: LTr, 2009.

ROMITA, ArionSayão. A subordinação no Contrato de Trabalho. São Paulo: LTr, 1979.

SLEE, Tom. Uberização: A Nova Onda do Trabalho Precarizado. Tradução: João Peres.São Paulo: Elefante, 2017.

SMITH, Adam. Riqueza das Nações. Ed. Condensada. Trad. Norberto de Paula Lima.

São Paulo: Folha de São Paulo, 2010.

VILHENA, Paulo Emílio Ribeiro. Relação de emprego: estrutura legal e supostos. 3. ed. São Paulo: LTr, 2005.

ZINGUEREVITCH, Alexandre. La Notion de Contrat de Travail. Paris: Pedone, 1936. 